\title{
A new scoring system for early diagnosis of ventilator- associated pneumonia: LUPPIS
}

Murat Haliloglu ${ }^{1}$, Beliz Bilgili ${ }^{1}$, Huseyin Bilginer ${ }^{2}$, Umut Sabri Kasapoglu ${ }^{1}$, Ismet Sayan ${ }^{1}$, Melek Suzer Aslan'1, Lutfiye Mulazimoglu Durmusoglu², Ismail Cinel ${ }^{1}$

${ }^{1}$ Department of Anesthesiology and Intensive Care, School of Medicine, Marmara University, Istanbul, Turkey

2Department of Infectious Disease, School of Medicine, Marmara University, Istanbul, Turkey

Submitted: 9 November 2017

Accepted: 5 February 2018

Arch Med Sci 2020; 16 (5): 1040-1048

DOI: https://doi.org/10.5114/aoms.2020.97965

Copyright $\odot 2020$ Termedia \& Banach

\section{Abstract}

Introduction: The Clinical Pulmonary Infection Score (CPIS) based on chest $X$-ray has been developed to facilitate clinical diagnosis of ventilator-associated pneumonia (VAP); however, this scoring system has a low diagnostic performance. We developed the Lung Ultrasound and Pentraxin-3 Pulmonary Infection Score (LUPPIS) for early diagnosis of VAP and evaluated the performance of this new scoring system.

Material and methods: In a prospective study of 78 patients with suspected VAP, we assessed the detection accuracy of LUPPIS for pneumonia in adult patients. We also evaluated the diagnostic performance of pentraxin-3 (PTX-3) findings of infection. On the day of the study, lung ultrasound was performed, PTX-3 levels were determined, and an endotracheal aspirate was obtained for Gram staining and culture.

Results: No significant differences were found between groups with respect to age, mechanical ventilation time, APACHE II score, or SOFA score $(p>0.05)$. Procalcitonin and PTX-3 levels were significantly higher in the $\operatorname{VAP}(+)$ group $(p<0.001$ and $p<0.001$, respectively). The threshold for LUPPIS in differentiating VAP $(+)$ patients from VAP $(-)$ patients was $>7$. In predicting VAP, LUPPIS $>7$ (sensitivity of $84 \%$, specificity of $87.7 \%$ ) was superior to CPIS $>6$ (sensitivity of $40.1 \%$, specificity of $84.5 \%$ ).

Conclusions: LUPPIS appears to provide better results in the prediction of VAP compared to CPIS, and the importance of lung ultrasound and PTX-3 is emphasized, which is a distinctive property of LUPPIS.

Key words: ventilator-associated pneumonia, Clinical Pulmonary Infection Score, lung ultrasound, pentraxin-3.

\section{Introduction}

Ventilator-associated pneumonia (VAP) is hospital-acquired pneumonia developing at least $48 \mathrm{~h}$ after intubation [1]. VAP is a common and severe problem in intensive care units (ICU) that affects $10 \%$ of critically ill patients receiving mechanical ventilation support, and there has been no decline in this rate in the last decade [2]. VAP prolongs mechanical ventilation (MV) time and the length of hospital stay, and it is associated with increased mortality (up to 70\%) [3-5]. VAP accounts for $50 \%$ of antibiotic consumption in the intensive care unit $[6,7]$.

\author{
Corresponding author: \\ Prof. Ismail Cinel \\ Department of Anesthesiology \\ and Intensive Care \\ School of Medicine \\ Marmara University \\ Istanbul, Turkey \\ E-mail: cinelismail@yahoo.com
}


Pentraxins are a family of a proteins involved in the acute phase inflammatory response. In response to inflammatory stimuli, C-reactive protein (CRP), which is a short pentraxin, and interleukin- 6 are produced in the liver [8]. Pentraxin-3 (PTX-3), the prototype of long pentraxins, primarily acts as a receptor in the activation of the immune system similar to short pentraxins [9]. However, this molecule differs from CRP in structure and gene organization, cellular source, stimuli resulting in its release, and ligand recognition pathways [10]. PTX-3 is elevated in many infections, and there is a correlation between its elevation and the severity of disease [11-13]. Diagnostic and prognostic performances of PTX-3 levels have been evaluated in the diagnosis of VAP; PTX-3 levels in bronchoalveolar lavage fluid were found to have diagnostic value, and plasma PTX-3 levels were found to have prognostic value [14].

Early diagnosis of VAP remains challenging for intensivists due to lack of a gold standard diagnostic method [1]. The diagnosis is primarily based on clinical findings, and the Clinical Pulmonary Infection Score (CPIS) has been developed to facilitate clinical diagnosis; however, this scoring system has a low diagnostic performance [15]. Lung ultrasound is becoming a widespread practice in evaluating lung pathologies in the ICU setting. It was suggested that a lung ultrasound score (LUS) could be reliably used in the diagnosis and follow-up of patients with VAP [16].

The aim of this study was to evaluate the performance of a new clinical scoring system for early diagnosis of VAP in critically in patients, which includes clinical infection signs, LUS score, and PTX-3 levels.

\section{Material and methods}

\section{Patient selection and study design}

This single-center, observational, prospective study (Ethics Committee approval number: 70737436-050.06.04) included 78 patients, who received therapy as an inpatient in the Intensive Care Unit between January 2015 and April 2016 and who were suspected of having VAP.

The suspicion of VAP was evaluated using classical clinical criteria: MV time $\geq 48 \mathrm{~h}$, new or progressive infiltrations on chest $\mathrm{X}$-ray and presence of two or more clinical criteria: fever $\left(\geq 38.5^{\circ} \mathrm{C}\right)$ or hypothermia $\left(<36.5^{\circ} \mathrm{C}\right)$, leukocytosis (white blood cell (WBC) count $>10^{4} / \mathrm{ml}$ ) or leukopenia (WBC count $<2.10^{3} / \mathrm{ml}$ ), and purulent tracheal secretions, $\mathrm{PaO}_{2} / \mathrm{FiO}_{2}<300$. Exclusion criteria were ongoing pneumonia, exacerbations of chronic obstructive pulmonary disease (COPD), those with non-pulmonary infection at the time of suspicion of VAP and contraindication to fiberoptic bronchoscopy.
Patients were included in the study at the time VAP was suspected. At inclusion we calculated CPIS, performed fiberoptic bronchoalveolar lavage (BAL), and endotracheal aspirate (EA) was obtained for Gram staining and culture. PTX-3, procalcitonin (PCT), and CRP serum levels, leukocyte count, body temperature, APACHE II score, SOFA score, and MV time were recorded. Temperature measurement was performed by the tympanic route. Lung ultrasound (LUS), BAL, and EA were performed in the first $8 \mathrm{~h}$ upon suspicion that VAP had emerged.

Venous blood samples from the patients were collected to measure serum PTX-3 levels. Thirty minutes after drawing blood samples, tubes were centrifuged for $10 \mathrm{~min}$ at $1500 \mathrm{rpm}$. Samples were aliquoted and stored at $-80^{\circ} \mathrm{C}$. Serum PTX-3 levels were measured using a commercial ELISA kit. PTX-3 concentrations in the samples were determined by comparing the optical density of each individual sample with the standard curve. The intra-assay coefficient of variation for the assay was 4-6\%.

Clinical samples for microbiological culture comprising BAL and cultures were processed using standard microbiological methods. Identification of isolates was performed with the VITEK (bioMérieux, Durham, NC) and API automated systems (bioMérieux, Marcy l'Etoile, France). VAP diagnosis was confirmed according to either tracheal culture positivity or, in tracheal culture-negative patients, the presence of all clinical criteria with an initiated or modified antibiotic regimen within $48 \mathrm{~h}$. The patients were retrospectively grouped as VAP (+) or VAP (-).

\section{Laboratory parameters}

Pentraxin-3, PCT and CRP levels were analyzed using the enzyme-linked immunosorbent assay (ELISA) test method (Boster Biological Technology Co. Ltd ELISA).

\section{LUS score}

Each hemithorax was assessed using a 1-5 MHz convex probe and by dividing the hemithorax into six areas: after dividing the hemithorax into anterior, lateral and posterior sections based on anterior and posterior axillary lines, each section was divided into superior and inferior halves (Figure 1) [17]. LUS score was calculated after ultrasound examination of the lungs [16]:

$-\geq 2$ areas with subpleural consolidation, 1 point; $-\geq 1$ area with dynamic arborescent/linear air bronchogram, 2 points.

\section{Score definition}

The Lung Ultrasound and Pentraxin-3 Pulmonary Infection Score (LUPPIS) recently de- 

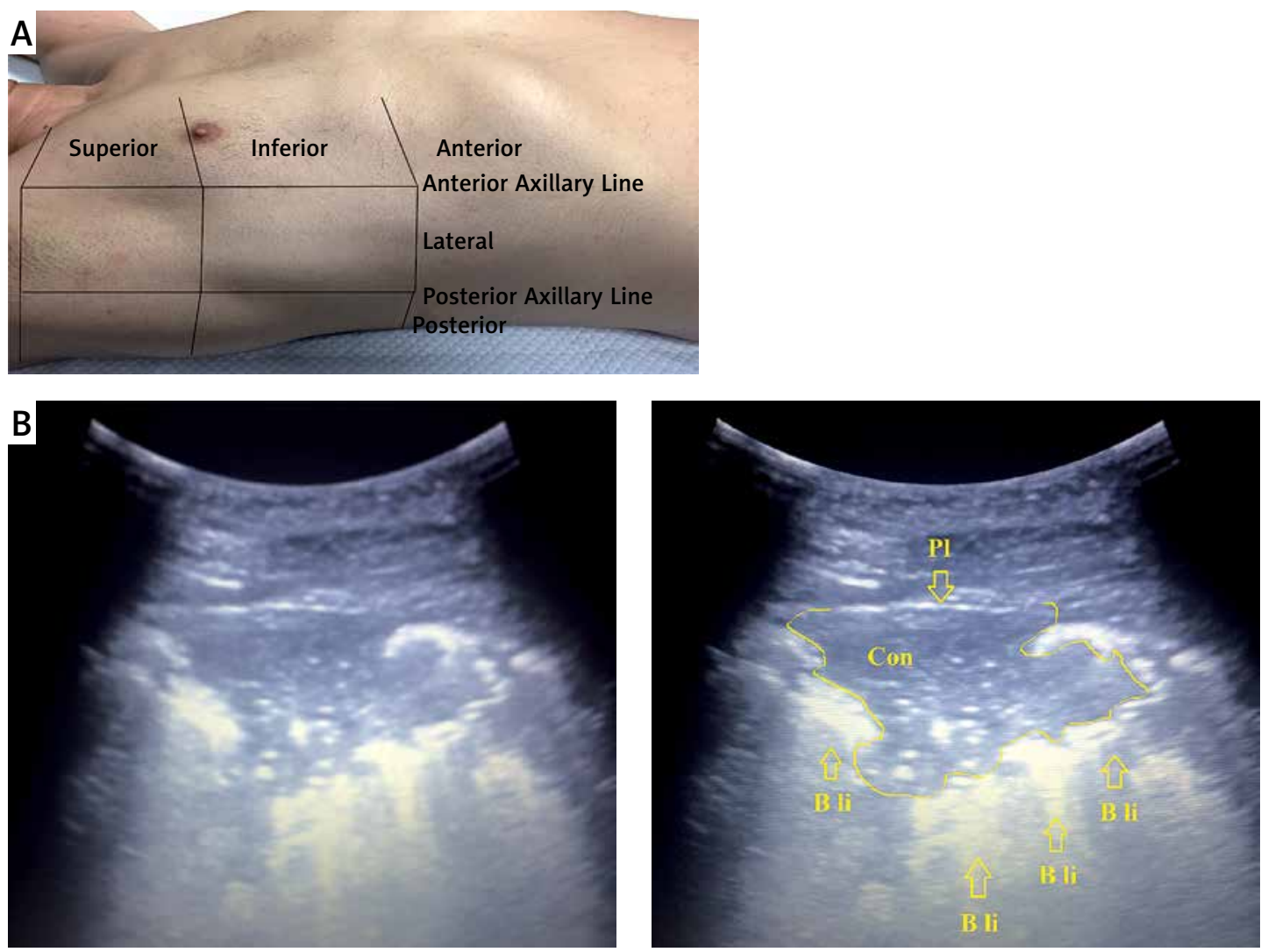

Figure 1. A - Lung ultrasonography. B - Appearance of subpleural consolidation on lung ultrasound. Air bronchogram with punctate echogenicity in the ground of hypoechoic subpleural consolidation

$P l$-pleural line, Con - consolidation, B li-B lines.

veloped by the authors included the following changes:

- Chest radiograph was replaced by LUS score;

- Leukocyte count was replaced by PTX-3 concentration;

- Culture of tracheal aspirate significance was considered positive if the count was $10^{4}$ colony-forming units/ml;

- Tracheal secretion was considered positive only if purulent. Definition of tracheal purulence was made by visual assessment by physicians.

The present study used CPIS as the control method, which is widely used in predicting VAP (Table I).

\section{Statistical analysis}

For this pilot study, we could not establish the number of patients needed or perform a power analysis. Consecutive patients were included as recommended [18]. R v.215.3 (R Core Team, 2013) software was used in statistical analyses. Statistical uncertainty was indicated by reporting $95 \% \mathrm{Cls}$. The data were expressed as mean, standard deviation, median, interquartile range, frequency, percentage, minimum and maximum. The Mann-Whitney $U$ test was used to check the difference of non-normally distributed variables between the two groups. Pearson's $\chi^{2}$ test and Fisher's exact test were used for comparison of nominal data. ROC curves were built, sensitivity and specificity of variables were calculated for various values, and the value of the highest Youden index was taken as a cut-off point. The areas under the ROC curves were compared using the Delong method. The level of statistical significance was set at $p<0.05$.

\section{Results}

The age of 78 patients included in the study ranged from 18 to 85 years, and the mean age was $58.14 \pm 16.72$ years. Of these patients, 32 were grouped as VAP (+), and 46 were grouped as VAP $(-)$. Of 32 patients diagnosed with ventilator-associated pneumonia, microbiologically confirmed VAP was detected in 26 patients. Microbiological analysis of the respiratory tract pathogens showed that $70 \%$ were Gram-negative organisms, $26.7 \%$ were Gram-positive organisms, and 3.3\% were Candida spp. In the Gram-negative bacilli group, was the most common species Acinetobacter baumannii (37.8\%), followed by Klebsiella pneumoniae, Pseudomonas aeruginosa, Escherichia coli, and Proteus mirabilis. In the Gram-positive cocci group, Staphylococcus aureus was the most 
Table I. Proposed LUPPIS compared with original CPIS

\begin{tabular}{|c|c|c|c|}
\hline \multirow[t]{2}{*}{ Parameter } & \multicolumn{3}{|c|}{ Points } \\
\hline & 0 & 1 & 2 \\
\hline \multicolumn{4}{|l|}{ CPIS: } \\
\hline Temperature $\left[{ }^{\circ} \mathrm{C}\right]$ & $\geq 36$ and $<38.4$ & $\geq 38.5$ and $<38.9$ & $<36$ or $\geq 39$ \\
\hline Blood leukocytes [WBC/mm³] & $\geq 4,000$ and $\leq 11,000$ & $<4,000$ or $>11,000$ & $\begin{array}{c}<4,000 \text { or }>11,000 \text { and } \\
\text { band forms } \geq 500\end{array}$ \\
\hline Oxygenation: $\mathrm{PaO}_{2} / \mathrm{FiO}_{2}$ & $>240$ or ARDS & & $\begin{array}{c}\leq 240 \text { and no evidence } \\
\text { of ARDS }\end{array}$ \\
\hline Tracheal secretions & Absent & Nonpurulent & Purulent \\
\hline Pulmonary radiography & No infiltrate & $\begin{array}{l}\text { Diffuse (or patchy) } \\
\text { infiltrate }\end{array}$ & Localized infiltrate \\
\hline Culture of tracheal aspirate & $\begin{array}{l}\text { Pathogenic bacteria } \\
\text { cultured in rare or small } \\
\text { quantity or no growth }\end{array}$ & $\begin{array}{l}\text { Pathogenic bacteria } \\
\text { cultured in moderate or } \\
\text { large quantity }\end{array}$ & $\begin{array}{c}\text { Same pathogenic } \\
\text { bacteria seen on Gram } \\
\text { stain }\end{array}$ \\
\hline \multicolumn{4}{|l|}{ LUPPIS: } \\
\hline Temperature $\left[{ }^{\circ} \mathrm{C}\right]$ & $\geq 36$ and $<38.4$ & $\geq 38.5$ and $<38.9$ & $<36$ or $\geq 39$ \\
\hline Pentraxin-3 [ng/ml] & $<2$ & & $\geq 2$ \\
\hline Oxygenation: $\mathrm{PaO}_{2} / \mathrm{FiO}_{2}$ & $>240$ or ARDS & & $\begin{array}{c}\leq 240 \text { and no evidence } \\
\text { of ARDS }\end{array}$ \\
\hline Tracheal secretions & Absent & Nonpurulent & Purulent \\
\hline LUS Score & & $\begin{array}{l}2 \text { areas with subpleural } \\
\text { consolidation }\end{array}$ & $\begin{array}{l}\geq 1 \text { areas with dynamic } \\
\text { arborescent/linear air } \\
\text { bronchogram }\end{array}$ \\
\hline Culture of tracheal aspirate & Negative & & Positive \\
\hline
\end{tabular}

ARDS - acute respiratory distress syndrome, CPIS - Clinically Pulmonary Infection Score, LUPPIS - Lung Ultrasound and Pentraxin-3 Pulmonary Infection Score, LUS - lung ultrasound.

prevalent. There were no significant differences between groups in age, MV time, leukocyte and CRP values, APACHE II score, or SOFA score $(p>0.05)$. PCT and PTX-3 levels were significantly higher in the VAP $(+)$ group $(p<0.001$ and $p<0.001$, respectively) (Table II).

The area under the curve was 1.000 in ROC curve analysis performed for PTX-3 (AUC
$(95 \% \mathrm{Cl})=1.000(1.000,1.000), p<0.001) . \mathrm{ROC}$ curve analysis for PTX-3 levels revealed an AUC of 0.832 (AUC $(95 \% \mathrm{Cl})=0.832(0.723,0.941)$, $p<0.001$ ) (Figure 2). The sensitivity for PTX-3 was $93.75 \%$, specificity was $100 \%$, positive predictive value (PPV) was $100 \%$, negative predictive value (NPV) was 95.8\%, and the cut-off level was $\geq 2$ (Table III). Accordingly, in the recently developed

Table II. Clinical characteristics of the patients

\begin{tabular}{|lccc|}
\hline Parameter & $\begin{array}{c}\text { VAP }(-) \\
(n=46)\end{array}$ & $\begin{array}{c}\text { VAP }(+) \\
(n=32)\end{array}$ & $P$-value \\
\hline Age [years] & $65(49,71)$ & $58.5(44,66.5)$ & 0.109 \\
\hline MV [days] & $7(5,10)$ & $8(5,12.5)$ & 0.426 \\
\hline CRP [ mg/l] & $210(117)$ & $186(194)$ & 0.11 \\
\hline Leukocytes [WBC/mm 3 ] & $12.5(9.8,15.9)$ & $14.1(11.1,18.9)$ & 0.326 \\
\hline APACHE II & $17(14,20)$ & $17(15,22)$ & 0.255 \\
\hline SOFA & $6(5,7)$ & $6.6(6,7.5)$ & 0.157 \\
\hline Procalcitonin $[\mathrm{ng} / \mathrm{ml}]$ & $0.3(0.13,0.46)$ & $1.95(0.66,2.61)$ & $<0.001$ \\
\hline PTX-3 [ng/ml] & $1.94(1.63,1.98)$ & $6.21(2.82,9.34)$ & $<0.001$ \\
\hline
\end{tabular}

MV - mechanical ventilation, APACHE II - Acute Physiology and Chronic Health Evaluation, SOFA - Sequential Organ Failure Score, $P T X-3$ - pentraxin 3, CRP - C-reactive protein. 


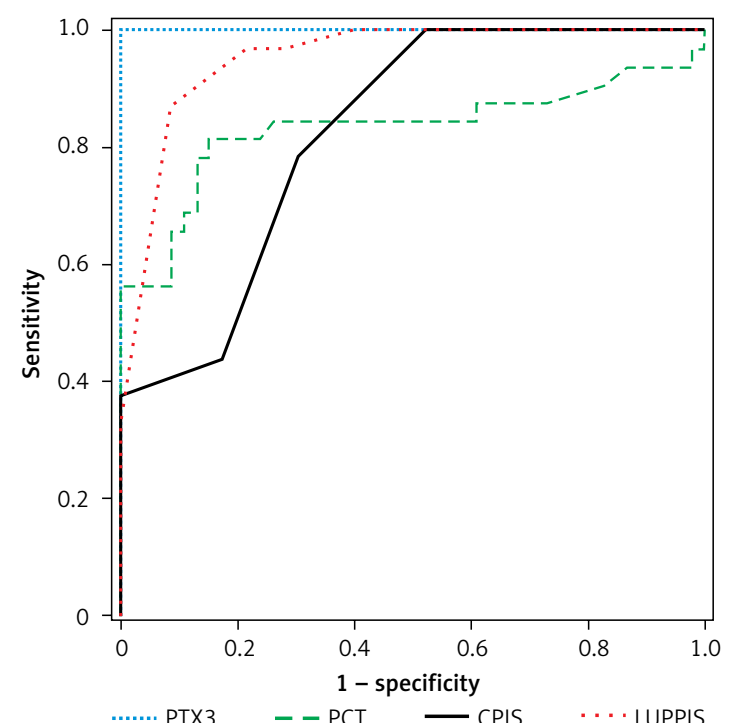

Figure 2. Comparison of areas under PTX3, PCT, CPIS and LUPPIS ROC curves
LUPPIS, the score was 0 points for patients with PTX-3 $<2$, and 2 points for patients with PTX-3 $\geq 2$.

The cut-off value for LUPPIS in differentiating patients with and without ventilator-associated pneumonia was $>7$ (sensitivity of $87.5 \%$, specificity of $91.3 \%$, PPV of $87.5 \%$, and NPV of $91.3 \%$ (Table IV). For CPIS > 6, sensitivity was $43.8 \%$, specificity was $82.6 \%$, PPV was $63.6 \%$, and NPV was $67.9 \%$ (Table V).

Although LUPPIS > 7 and CPIS > 6 yield comparable specificity, sensitivity of LUPPIS $>7$ was higher compared with CPIS $>6$. The risk of having VAP was 73.50-fold higher in patients with LUPPIS > 7 compared to patients with LUPPIS $\leq 7$ $(\mathrm{OR}(95 \% \mathrm{Cl})=73.50(16.97,318.42), p<0.001)$. The OR for CPIS $>6$ was $3.69(\mathrm{OR}(95 \% \mathrm{Cl})=3.69$ (1.31, 10.39), $p<0.001)$.

The AUC was 0.822 in ROC curve analysis for CPIS (AUC $(95 \% \mathrm{Cl})=0.822(0.719,0.899), p<$ 0.001 ) (Figure 2). The AUC was 0.952 in ROC curve

Table III. Assessment of cut-off values for pentraxin-3

\begin{tabular}{|lcccc|}
\hline PTX-3 & Sensitivity $(95 \% \mathrm{Cl})$ & Specificity $(95 \% \mathrm{Cl})$ & PPV $(95 \% \mathrm{Cl})$ & $\mathrm{NPV}(95 \% \mathrm{Cl})$ \\
\hline$>0.97$ & $100(89.1,100.0)$ & $15.22(6.3,28.9)$ & $45.1(33.2,57.3)$ & $100(59.0,100.0)$ \\
\hline$>1.54$ & $100(89.1,100.0)$ & $21.74(10.9,36.4)$ & $47.1(34.8,59.6)$ & $100(69.2,100.0)$ \\
\hline$>1.906$ & $100(89.1,100.0)$ & $43.48(28.9,58.9)$ & $55.2(41.5,68.3)$ & $100(83.2,100.0)$ \\
\hline$>1.98$ & $100(89.1,100.0)$ & $80.43(66.1,90.6)$ & $78(62.4,89.4)$ & $100(90.5,100.0)$ \\
\hline$>2$ & $93.75(79.2,99.2)$ & $100(92.3,100.0)$ & $100(88.4,100.0)$ & $95.8(85.7,99.5)$ \\
\hline$>2.17$ & $87.5(71.0,96.5)$ & $100(92.3,100.0)$ & $100(87.7,100.0)$ & $92(80.8,97.8)$ \\
\hline$>6.18$ & $50(31.9,68.1)$ & $100(92.3,100.0)$ & $100(79.4,100.0)$ & $74.2(61.5,84.5)$ \\
\hline$>9.03$ & $28.12(13.7,46.7)$ & $100(92.3,100.0)$ & $100(66.4,100.0)$ & $66.7(54.3,77.6)$ \\
\hline$>13.9$ & $0(0.0,10.9)$ & $100(92.3,100.0)$ & 0 & $59(47.3,70.0)$ \\
\hline
\end{tabular}

PPV - positive predictive value, NPV - negative predictive value, PTX-3-pentraxin 3.

Table IV. Assessment of cut-off values for LUPPIS

\begin{tabular}{|lcccc|}
\hline LUPPIS & Sensitivity $(95 \% \mathrm{Cl})$ & Specificity $(95 \% \mathrm{Cl})$ & PPV $(95 \% \mathrm{Cl})$ & $\mathrm{NPV}(95 \% \mathrm{Cl})$ \\
\hline$>2$ & $100(89.1,100.0)$ & $28.3(16.0,43.5)$ & $49.2(36.6,61.9)$ & $100(75.3,100.0)$ \\
\hline$>3$ & $100(89.1,100.0)$ & $52.2(36.9,67.1)$ & $59.3(45.0,72.4)$ & $100(85.8,100.0)$ \\
\hline$>4$ & $100(89.1,100.0)$ & $60.9(45.4,74.9)$ & $64(49.2,77.1)$ & $100(87.7,100.0)$ \\
\hline$>5$ & $96.9(83.8,99.9)$ & $71.7(56.5,84.0)$ & $70.5(54.8,83.2)$ & $97.1(84.7,99.9)$ \\
\hline$>6$ & $96.9(83.8,99.9)$ & $78.3(63.6,89.1)$ & $75.6(59.7,87.6)$ & $97.3(85.8,99.9)$ \\
\hline$>7$ & $87.5(71.0,96.5)$ & $91.3(79.2,97.6)$ & $87.5(71.0,96.5)$ & $91.3(79.2,97.6)$ \\
\hline$>8$ & $34.4(18.6,53.2)$ & $100(92.3,100.0)$ & $100(71.5,100.0)$ & $68.7(56.2,79.4)$ \\
\hline$>9$ & $25(11.5,43.4)$ & $100(92.3,100.0)$ & $100(63.1,100.0)$ & $65.7(53.4,76.7)$ \\
\hline$>10$ & $12.5(3.5,29.0)$ & $100(92.3,100.0)$ & $100(39.8,100.0)$ & $62.2(50.1,73.2)$ \\
\hline$>11$ & $0(0.0,10.9)$ & $100(92.3,100.0)$ & 0 & $59(47.3,70.0)$ \\
\hline
\end{tabular}

PPV - positive predictive value, NPV - negative predictive value, LUPPIS - Lung Ultrasound and Pentraxin-3 Pulmonary Infection Score. 
Table V. Assessment of cut-off values for CPIS

\begin{tabular}{|lcccc|}
\hline CPIS & Sensitivity $(95 \% \mathrm{Cl})$ & Specificity $(95 \% \mathrm{Cl})$ & PPV $(95 \% \mathrm{Cl})$ & NPV $(95 \% \mathrm{Cl})$ \\
\hline$>3$ & $100(89.1,100.0)$ & $21.7(10.9,36.4)$ & $47.1(34.8,59.6)$ & $100(69.2,100.0)$ \\
\hline$>4$ & $100(89.1,100.0)$ & $47.8(32.9,63.1)$ & $57.1(43.2,70.3)$ & $100(84.6,100.0)$ \\
\hline$>5$ & $78.1(60.0,90.7)$ & $69.6(54.2,82.3)$ & $64.1(47.2,78.8)$ & $82.1(66.5,92.5)$ \\
\hline$>6$ & $43.8(26.4,62.3)$ & $82.6(68.6,92.2)$ & $63.6(40.7,82.8)$ & $67.9(54.0,79.7)$ \\
\hline$>7$ & $37.5(21.1,56.3)$ & $100(92.3,100.0)$ & $100(73.5,100.0)$ & $69.7(57.1,80.4)$ \\
\hline$>8$ & $21.9(9.3,40.0)$ & $100(92.3,100.0)$ & $100(59.0,100.0)$ & $64.8(52.5,75.8)$ \\
\hline$>9$ & $18.8(7.2,36.4)$ & $100(92.3,100.0)$ & $100(54.1,100.0)$ & $63.9(51.7,74.9)$ \\
\hline$>10$ & $6.3(0.8,20.8)$ & $100(92.3,100.0)$ & $100(15.8,100.0)$ & $60.5(48.6,71.6)$ \\
\hline$>11$ & $0(0.0,10.9)$ & $100(92.3,100.0)$ & 0 & $59(47.3,70.0)$ \\
\hline
\end{tabular}

PPV - positive predictive value, NPV - negative predictive value, CPIS - Clinically Pulmonary Infection Score.

Table VI. Comparison of areas under ROC curves for CPIS and LUPPIS

\begin{tabular}{|lccccc|}
\hline Parameter & Area & Standard error & \multicolumn{2}{c|}{$95 \%$ confidence interval } & P-value \\
\cline { 3 - 5 } & & & Lower & Upper & \\
\hline CPIS & 0.822 & 0.046 & 0.719 & 0.899 & $<0.001$ \\
\hline LUPPIS & 0.952 & 0.022 & 0.879 & 0.988 & $<0.001$ \\
\hline Difference & 0.130 & 0.040 & 0.051 & 0.209 & 0.001 \\
\hline
\end{tabular}

CPIS - Clinically Pulmonary Infection Score, LUPPIS - Lung Ultrasound and Pentraxin-3 Pulmonary Infection Score.

analysis for LUPPIS (AUC $(95 \% \mathrm{CI})=0.952(0.879$, $0.988), p<0.001$ ) (Figure 2). The difference between the areas under the ROC curves was found to be 0.130 using the DeLong method, and this difference was statistically significant $(p=0.001)$ (Table VI).

\section{Discussion}

\section{General opinions}

In the present study, the utility of the new scoring system (LUPPIS) which was developed by the authors and based on five parameters - lung ultrasound, PTX-3 values, oxygenation, body temperature, and tracheal aspirate culture - was evaluated, and LUPPIS was shown to be a valuable method for the diagnosis of VAP.

Many non-infectious processes may cause fever and pulmonary infiltration in patients receiving mechanical ventilatory support, and for this reason, symptoms of VAP are nonspecific [15]. The clinical approach suggests initiation of broad-spectrum antibiotics to all patients suspected of having VAP [1]. However, this approach results in an increased rate of multi-drug resistant bacterial strains $[19,20]$. Treatment of microbiologically diagnosed patients only may cause a delay in the initiation of antibiotics and increase mortality [21, 22]. Initiation of appropriate antibiotics without wasting time while avoiding these two extreme approaches is possible with early diagnostic methods for VAP.

In the earliest study, which included 28 patients, CPIS > 6 showed a sensitivity of $93 \%$ and a specificity of $100 \%$ in predicting VAP [23]. However, later studies that compared CPIS with pathological diagnosis [15] and diagnosis based on bronchoalveolar liquid culture [24] have reported low diagnostic performance for CPIS in predicting VAP. Modified CPIS incorporating Gram staining has shown improved diagnostic performance and sensitivity, but specificity remained at a suboptimal level [24]. Although CPIS has little diagnostic value for VAP, it is currently the most commonly used scoring system.

\section{Pentraxin-3}

Soluble triggering receptor expressed on myeloid cells type 1 (STREM-1), PCT, and CRP are distinguished from other markers playing a supporting role in the diagnosis and management of ventilator-associated pneumonia; however, these markers have variable sensitivities and specificities in predicting VAP [25].

PTX-3, an acute phase inflammatory protein, is locally produced in the infection area, epithelium, endothelial cells, and leukocytes, and plasma levels of PTX-3 correlate with the severity of disease $[26,27]$. PTX-3 levels increase within $6-8 \mathrm{~h}$ in 
endotoxic shock and sepsis and reach peak concentrations [28-30]. There is a lack of sufficient information regarding its half-life; however, exogenously administered PTX-3 was shown to have a half-life of $1 \mathrm{~h}$ [31]. In an experimental pneumonia model, PTX-3 was shown to differentiate various causes of infections (i.e. bacteria, virus, fungus) [32-34]. Also, plasma PTX-3 levels were also shown to be elevated in VAP and community-acquired pneumonia [11,35]. In the study by Mauri et al., PTX-3 levels in bronchoalveolar lavage fluid of intubated patients in the ICU were shown to be an early marker of pneumonia with high negative predictive value [14]. Despite the limited number of clinical studies available, PTX-3 is a promising biomarker that could be used in early diagnosis of community-acquired and healthcare-related pneumonia [36]. We, therefore, selected PTX-3 in LUPPIS instead of leukocyte count, which is used in CPIS.

\section{LUS}

The diagnosis and follow-up of VAP are currently based on chest X-ray; however, bedside chest $\mathrm{X}$-ray offers poor quality and limited reliability [37-40]. Of patients receiving mechanical ventilatory support in the ICU, $38 \%$ have an abnormal appearance in their chest X-rays [41]. Pulmonary infiltrations due to non-infectious causes often complicate detection of infiltrations due to VAP in critically ill patients [16]. The likelihood of an opacity observed on a chest X-ray being due to pneumonia ranges from 27 to $35 \%$ [42, 43]. Also, the limited diagnostic performance of bedside chest X-ray [40] complicates detection of VAP. The LUS, the use of which is recommended in critically ill patients [44], provides reliable information about the condition [45], aeration [46], perfusion [47], and morphology [48] of the lungs. The use of lung ultrasonography in the ICU is becoming more prevalent [49] than the chest X-ray with the advantages of being a non-invasive, easily reproducible method with the availability of bedside application and a short learning period [50].

\section{LUPPIS}

VAP is multifocal process with different histopathological patterns, so single consolidation in LUS is unlikely to show sufficient sensitivity and specificity for pneumonia [16]. In addition, Mongodi et al. reported that high sensitivity but poor specificity for small subpleural consolidation and high specificity but poor sensitivity for consolidations with dynamic air bronchograms [16]. Regarding the use of LUS in conjunction with laboratory tests, a retrospective study combining consolida- tion on lung ultrasound with procalcitonin levels showed it to be superior to CPIS in predicting VAP [51]. Mongodi et al. also reported high specificity for one or more areas with small subpleural consolidations detected on LUS when associated with a positive culture of tracheal aspirate [16]. In our study, we found that simple changes in some parameters (e.g., chest radiography and leukocyte count were replaced with LUS score and PTX-3 level, respectively) significantly increased both the sensitivity and the specificity of LUPPIS.

\section{Limitations}

Our study has several limitations, due to which it should be considered a pilot, exploratory analysis of a new type of score. LUS is operator-dependent, and the operator must receive training. Obese patients with subcutaneous emphysema or large thoracic wound dressings may pose difficulties in lung ultrasound, and this may affect diagnostic performance of the scoring system. The present study was conducted only on 78 patients; the results of this study must be evaluated in a larger population. The studies that showed the CPIS score not to be accurate recruited 700 patients, so we cannot exclude that the present study may be underpowered.

In conclusion, the present study attempted to introduce a fast, cheap, and reliable approach to the diagnosis of VAP using the bedside applicability advantages of lung ultrasound. For this purpose, we made some changes in the parameters of commonly used CPIS and developed a new scoring system incorporating the LUS score and PTX-3, showing good diagnostic performance in VAP.

\section{Conflict of interest}

The authors declare no conflict of interest.

\section{References}

1. Kalil AC, Metersky ML, Klompas M, et al. Management of adults with hospital-acquired and ventilator-associated pneumonia: 2016 clinical practice guidelines by the Infectious Diseases Society of America and the American Thoracic Society. Clin Infect Dis 2016; 63: e61-111.

2. Wang $\mathrm{Y}$, Eldridge N, Metersky ML, et al. National trends in patient safety for four common conditions, 20052011. N Engl J Med 2014; 370: 341-51.

3. Tejerina E, Frutos-Vivar F, Restrepo MI, et al. Incidence, risk factors, and outcome of ventilator-associated pneumonia. J Crit Care 2006; 21: 56-65.

4. Rello J, Ollendorf DA, Oster G, et al. Epidemiology and outcomes of ventilator-associated pneumonia in a large US database. Chest 2002; 122: 2115-21.

5. Melsen WG, Rovers MM, Koeman M, Bonten MJ. Estimating the attributable mortality of ventilator-associated pneumonia from randomized prevention studies. Crit Care Med 2011; 39: 2736-42. 
6. Melsen WG, Rovers MM, Groenwold RH, et al. Attributable mortality of ventilator-associated pneumonia: a meta-analysis of individual patient data from randomised prevention studies. Lancet Infect Dis 2013; 13: 665-71.

7. Bekaert M, Timsit JF, Vansteelandt S, et al. Attributable mortality of ventilator-associated pneumonia: a reappraisal using causal analysis. Am J Respir Crit Care Med 2011; 184: 1133-9.

8. Gewurz H, Mold C, Siegel J, Fiedel B. C-reactive protein and the acute phase response. Ad Intern Med 1981; 27: 345-72.

9. Breviario F, d' Aniello EM, Golay J, et al. Interleukin-1-inducible genes in endothelial cells. Cloning of a new gene related to C-reactive protein and serum amyloid P component. J Biol Chem 1992; 267: 22190-7.

10. Bottazzi B, Vouret-Craviari V, Bastone A, et al. Multimer formation and ligand recognition by the long pentraxin ptx3 similarities and differences with the short pentraxins c-reactive protein and serum amyloid p component. J Biol Chem 1997; 272: 32817-23.

11. Lin Q, Fu F, Shen L, Zhu B. Pentraxin 3 in the assessment of ventilator-associated pneumonia: an early marker of severity. Heart Lung 2013; 42: 139-45.

12. Bastrup-Birk S, Skjoedt MO, Munthe-Fog L, Strom J), Ma YJ, Garred P. Pentraxin-3 serum levels are associated with disease severity and mortality in patients with systemic inflammatory response syndrome. PLoS One 2013; 8: e73119.

13. Uusitalo-Seppälä R, Huttunen R, Aittoniemi J, et al. Pentraxin 3 (PTX3) is associated with severe sepsis and fatal disease in emergency room patients with suspected infection: a prospective cohort study. PLoS One 2013; 8: e53661.

14. Mauri T, Coppadoro A, Bombino M, et al. Alveolar pentraxin 3 as an early marker of microbiologically confirmed pneumonia: a threshold-finding prospective observational study. Crit Care 2014; 18: 562.

15. Fàbregas N, Ewig S, Torres A, et al. Clinical diagnosis of ventilator associated pneumonia revisited: comparative validation using immediate post-mortem lung biopsies. Thorax 1999; 54: 867-73.

16. Mongodi S, Via G, Girard M, et al. Lung ultrasound for early diagnosis of ventilator-associated pneumonia. Chest 2016; 149: 969-80.

17. Bouhemad B, Brisson H, Le-Guen M, Arbelot C, Lu Q Rouby JJ. Bedside ultrasound assessment of positive end-expiratory pressure-induced lung recruitment. Am J Respir Crit Care Med 2011; 183: 341-7.

18. Bossuyt PM, Reitsma JB, Bruns DE, et al. The STARD statement for reporting studies of diagnostic accuracy: explanation and elaboration. Ann Inter Med 2003; 138 W1-12.

19. Trouillet JL, Chastre J, Vuagnat A, et al. Ventilator-associated pneumonia caused by potentially drug-resistant bacteria. Am J Respir Crit Care Med 1998; 157: 531-9.

20. Yu V, Singh N. Excessive antimicrobial usage causes measurable harm to patients with suspected ventilator-associated pneumonia. Intensive Care Med 2004; 30: 735-8.

21. Dellinger RP, Levy MM, Carlet JM, et al. Surviving sepsis campaign: international guidelines for management of severe sepsis and septic shock: 2008. Intensive Care Med 2008; 34: 17-60.

22. Ibrahim EH, Sherman G, Ward S, Fraser VJ, Kollef $\mathrm{MH}$. The influence of inadequate antimicrobial treatment of bloodstream infections on patient outcomes in the ICU setting. Chest 2000; 118: 146-55.
23. Pugin J, Auckenthaler R, Mili N, Janssens JP, Lew PD, Suter PM. Diagnosis of ventilator-associated pneumonia by bacteriologic analysis of bronchoscopic and nonbronchoscopic "blind" bronchoalveolar lavage fluid. Am Rev Respir Dis 1991; 143: 1121-9.

24. Fartoukh M, Maître B, Honoré S, Cerf C, Zahar JR, Brun-Buisson C. Diagnosing pneumonia during mechanical ventilation: the clinical pulmonary infection score revisited. Am J Respir Crit Care Med 2003; 168: 173-9.

25. Palazzo SJ, Simpson T, Schnapp L. Biomarkers for ventilator-associated pneumonia: review of the literature. Heart Lung 2011; 40: 293-8.

26. Mizgerd JP. Acute lower respiratory tract infection. N Engl J Med 2008; 358: 716-27.

27. Diamond JM, Meyer NJ, Feng R, et al. Variation in PTX3 is associated with primary graft dysfunction after lung transplantation. Am J Respir Crit Care Med 2012; 186: 546-52.

28. Inforzato A, Bottazzi B, Garlanda C, Valentino S, Mantovani $A$. Pentraxins in humoral innate immunity. Adv Exp Med Biol 2012; 946: 1-20.

29. Holmskov U, Thiel S, Jensenius JC. Collectins and ficolins: humoral lectins of the innate immune defense. Annu Rev Immunol 2003; 21: 547-78.

30. Han B, Mura M, Andrade CF, et al. TNFalpha-induced long pentraxin PTX3 expression in human lung epithelial cells via JNK. J Immunol 2005; 175: 8303-11.

31. Deban L, Russo RC, Sironi M et al. Regulation of leukocyte recruitment by the long pentraxin PTX3. Nat Immunol 2010; 11: 328-34.

32. Moalli F, Paroni M, Rodriguez TV, et al. The therapeutic potential of the humoral pattern recognition molecule PTX3 in chronic lung infection caused by Pseudomonas aeruginosa. J Immunol 2011; 186: 5425-34.

33. Reading PC, Bozza S, Gilbertson B, et al. Antiviral activity of the long chain pentraxin PTX3 against influenza viruses. J Immunol 2008; 180: 3391-8.

34. Giudice PL, Campo S, Verdoliva A, et al. Efficacy of PTX3 in a rat model of invasive aspergillosis. Antimicrob Agents Chemother 2010; 54: 4513-5.

35. Kao SJ, Yang HW, Tsao SM, et al. Plasma long pentraxin 3 (PTX3) concentration is a novel marker of disease activity in patients with community-acquired pneumonia. Clin Chem Lab Med 2013; 51: 907-13.

36. Sönmezer MÇ, Tülek N. Bakteriyel İnfeksiyonlarda ve Sepsiste Biyobelirteçler. Klimik Dergisi 2015; 28: 96-102.

37. Graat ME, Choi G, Wolthuis EK, et al. The clinical value of daily routine chest radiographs in a mixed medical-surgical intensive care unit is low. Crit Care 2005; 10: R11.

38. Graat ME, Kröner A, Spronk PE, et al. Elimination of daily routine chest radiographs in a mixed medical-surgical intensive care unit. Intensive Care Med 2007; 33: 639-44.

39. Kröner A, Binnekade JM, Graat ME, et al. On-demand rather than daily-routine chest radiography prescription may change neither the number nor the impact of chest computed tomography and ultrasound studies in a multidisciplinary intensive care unit. Anesthesiology 2008; 108: 40-5

40. Lichtenstein D, Goldstein I, Mourgeon E, Cluzel P, Grenier P, Rouby J. Comparative diagnostic performances of auscultation, chest radiography, and lung ultrasound in acute respiratory distress syndrome. Anesthesiology 2004; 100: 9-15.

41. Nseir S, Favory R, Jozefowicz E, et al. Antimicrobial treatment for ventilator-associated tracheobronchitis: a randomized, controlled, multicenter study. Crit Care 2008; 12: R62. 
42. Lefcoe MS, Fox GA, Leasa DJ, Sparrow RK, McCormack DG. Accuracy of portable chest radiography in the critical care setting. Diagnosis of pneumonia based on quantitative cultures obtained from protected brush catheter. Chest 1994; 105: 885-7.

43. Wunderink RG, Woldenberg LS, Zeiss J, Day CM, Ciemins J, Lacher DA. The radiologic diagnosis of autopsy-proven ventilator-associated pneumonia. Chest 1992; 101: 458-63.

44. Volpicelli G, Elbarbary M, Blaivas M, et al. International evidence-based recommendations for point-of-care lung ultrasound. Intensive Care Med 2012; 38: 577-91.

45. Bouhemad B, Zhang M, Lu Q, Rouby JJ. Clinical review: bedside lung ultrasound in critical care practice. Crit Care 2007; 11: 205.

46. Soummer A, Perbet S, Brisson H, et al. Ultrasound assessment of lung aeration loss during a successful weaning trial predicts postextubation distress. Crit Care Med 2012; 40: 2064-72.

47. Bouhemad B, Barbry T, Soummer A, Lu Q, Rouby J. Doppler study of the effects of inhaled nitric oxide and intravenous almitrine on regional pulmonary blood flows in patients with acute lung injury. Minerva Anestesiol 2014; 80: 517-25.

48. Arbelot C, Ferrari F, Bouhemad B, Rouby JJ. Lung ultrasound in acute respiratory distress syndrome and acute lung injury. Curr Opin Crit Care 2008; 14: 70-4.

49. Zieleskiewicz L, Muller L, Lakhal K, et al. Point-of-care ultrasound in intensive care units: assessment of 1073 procedures in a multicentric, prospective, observational study. Intensive Care Med 2015; 41: 1638-47.

50. Noble VE, Lamhaut L, Capp R, et al. Evaluation of a thoracic ultrasound training module for the detection of pneumothorax and pulmonary edema by prehospital physician care providers. BMC Med Educ 2009; 9: 3 .

51. Zagli G, Cozzolino M, Terreni A, Biagioli T, Caldini AL, Peris A. Diagnosis of ventilator-associated pneumonia: a pilot, exploratory analysis of a new score based on procalcitonin and chest echography. Chest 2014; 146: 1578-85. 